Article

\title{
'Better as a Buddhist': An Interpretative Phenomenological Analysis of the Reflections on the Religious Beliefs of Buddhist Men Serving a Prison Sentence for a Sexual Offence
}

\author{
Katie Bell ${ }^{1}$, Belinda Winder ${ }^{2, *(1)}$ and Nicholas Blagden ${ }^{2}$ \\ 1 HMP Whatton, HMPPS, Nottingham NG13 9FQ, UK; katie.bell@hmps.gsi.gov.uk \\ 2 Sexual Offences, Crime and Misconduct Research Unit, Psychology, School of Social Sciences, \\ Nottingham Trent University, Nottingham NG1 4FQ, UK; Nicholas.Blagden2@ntu.ac.uk \\ * Correspondence: belinda.winder@ntu.ac.uk; Tel.: +44-115-848-5525
}

Received: 7 March 2018; Accepted: 27 March 2018; Published: 29 March 2018

\begin{abstract}
This paper presents a qualitative analysis of the accounts offered by individuals $(n=7)$ convicted of a sexual offense who describe themselves as Buddhists. Data were collected through semi-structured interviews within a custodial environment and analyzed using interpretative phenomenological analysis (IPA). This paper presents the two superordinate themes that emerged from the data: (i) Better as a Buddhist and (ii) Ebb and Flow. Reflections and analysis from the Buddhist prison chaplain are integrated within the analysis of prisoner-participant data. Implications of the analysis are discussed with reference to interventions that use Buddhist principles, factors that underpin factors that help reduce reoffending and those that fit with the formation of a desistance narrative for religious individuals who have committed sexual offenses
\end{abstract}

Keywords: Buddhism; qualitative; sexual offense; interpretative phenomenological analysis

\section{Introduction}

The purpose of prisons has changed over time. Initially, prisons were promulgated as a place of punishment; increasingly, they came to be places of rehabilitation ( $\left.\mathrm{O}^{\prime} \mathrm{Connor} 2005\right)$. Religion has been entwined with the concept of rehabilitation from its nascence, with the earliest ideas of rehabilitation involving religion as a correctional intervention. This included religious activity and the atonement for sinful behavior as the focus of individuals' sentences ( $\mathrm{O}^{\prime}$ Connor 2005). Over time, and with a move toward a more secular society, religion has become separated from rehabilitation, with the latter now comfortably ensconced alongside psychology. Despite this, many prisoners still identify as religious and/or find religion and/or convert to a different religion while in custody. As such, there continues to be a strong religious presence within prisons, with the prison service chaplaincy accommodating a range of faiths. In the site of the present study, 72 percent of the prisoners identified as religious, with 7.6 percent (5.5 percent of the total population for the prison) registered Buddhists (Jo Honour, Coordinating Chaplain, personal communication, 2017).

The changing role of religion in society is echoed by the changing perception of what it means to be religious in prison: more cynical attitudes to religion "on the outside" find parallels with more skeptical attitudes to those in prison who self-identify as religious. Whilst some evidence suggests that prisoners who "find" religion while incarcerated believe that this will indeed help them to desist from offending in the future (Clear and Sumter 2002), prison staff may take a more cynical stance. Prison staff (and indeed the general public) may conclude that prisoners self-identify as religious to take advantage of a range of benefits, both major and minor. Clear et al. 's study (2000) suggests 
that long-term prisoners may think that being religious will be viewed positively by a parole board when making decisions about their possible release. Minor benefits may include apparently trivial things, such as eating meals that are different to the standard fare, or receiving visits from sessional chaplains, brought in from the outside. This may not seem much of a benefit; however, prisoners relish the opportunity to interact with staff who have not been saturated by working constantly within the prison system and who therefore may help prisoners to feel more "normal" and less like a prisoner.

There has been a plethora of research examining the putative impact of religion on desistance from offending, seeking to explain how religion may inhibit an individual from continuing to commit crime (Hallett and McCoy 2015; Salas-Wright et al. 2016; Eshuys and Smallbone 2006; Kewley et al. $(2015,2016))$. As a mainstream religion in Western society, Christianity is typically the religion that is the focus for this type of research. Such studies have predominantly reported an inverse relationship between religion and offending, although this is not consistently the case (Clear and Sumter 2002). Researchers have subsequently proceeded to generalize these findings from Christianity to all religions, echoing early research difficulties in the psychological study of religion when Christianity dominated people's construal of what a religion was. Yet religions vary in personality, practice, and reputation. Generalizing religious desistance research from studies predominantly conducted in the US, including high proportions of Christian participants, and with many prisoners serving prison sentences for violent/anti-social crimes, has limitations. Examining why people have desisted from crime, through the analysis of rich, idiographic data, allows us to conceptualize the mechanisms through which each faith may inhibit reoffending. Where the type of offense is driven by different motivations and risk factors to generic violent/anti-social offending, as is the case with sexual offenses (Mann et al. 2010), idiographic data additionally offers explanatory depth to the quantitative association between desistance and faith.

Sexual crime is increasingly being recognized as a serious societal concern. Secondary prevention initiatives, such as Dunkelfeld in Germany (Beier et al. 2009), the work of the Lucy Faithfull Foundation and Safer Living Foundation in the UK (Winder et al. 2017), and the Utah Prevention Project in the US are emerging across the world. The number of people being convicted of sexual offenses is rising in the UK, with the highest number of sexual offenses (since national recordkeeping commenced) being reported in December 2015. For the first time, the total number of sexual offenses in a year exceeded 100,000 (Office for National Statistics 2015). The number of individuals who have been convicted of a sexual offense has risen by 9 percent in the past 12 months, with the total now at 12,771 sentenced individuals, representing 15 percent of the total prison population (Offender Management Service 2016). This means that an increasing number of people who have been convicted of a sexual offense will now be living in the community. For these individuals, nasty societal attitudes to "sex offenders" will be just one of the challenges they face on release from prison.

Kewley et al. (2016) highlighted how religious prisoners could find that the process of reintegrating with society is helped by their engagement with a religious group or community, yet the authors state: "However, some caution is needed as the transition from offender to non-offender was not seamless or straightforward for those with an innate sexual interest in children" (p. 21). This is one element that distinguishes sexual offenses from other types of offenses, as sexual interest can be difficult or sometimes impossible to change (Beckstead 2012). With sexual offenders, reintegration can also be far more difficult (Harper et al. 2017), yet emotional isolation is also a dynamic risk factor for sexual reoffense. The capacity to engage with a social group, and to identify with them, could function as a protective factor; moreover, engagement with a social group in the community could help to reduce the "social curse" (Stevenson et al. 2014) that the label of "sex offender" brings with it.

Although the interrelationships between religion and desistance of sexual offenses has only recently started to be investigated, there have been several studies examining the interrelationships between religion and desistance from generic, non-sexual, offending (McGuire 2013). Offending behavior programs have been developed and adapted over time to reduce an individual's likelihood of reoffending. In recent years, techniques such as mindfulness have been introduced, 
and there are a number of studies highlighting its potential effectiveness within offender populations (Bowen et al. 2006; Dunn 2010). This technique stems from Buddhist practice and has been present for hundreds of years, with Buddhists all over the world engaging in mindfulness on a daily basis. Research has reported that practicing mindfulness is an effective therapy for a variety of psychological problems, being especially effective at reducing anxiety, depression, and stress (Khoury et al. 2013). Researchers have reported that participants that engaged in mindfulness and other Buddhist-derived interventions showed improvements across a range of criminogenic variables, including substance abuse (Simpson et al. 2007), anger and impulse control (Derezotes 2000), hostility (Dunn 2010), relaxation (Derezotes 2000), self-esteem (Dunn 2010), and increased optimism (Bowen et al. 2006). These Buddhist practices have now been included in mainstream sex offender treatment programs run by the UK prison service.

During a period of custody, an individual's religious practice is unlikely to be considered unless it has been found to be directly linked to their risk of reoffending. This is also the case within structured risk assessments that are often completed, particularly with long-term prisoners. With the current movement to consider and develop individuals' protective factors (De Vries Robbé et al. 2015), it is possible that religiosity could play a more important role in the future as elements of religious behavior could assist in protecting individuals from future offending. This study attempts to develop an understanding of the role Buddhism plays in the lives of men convicted of sexual offenses as a starting point for considering the role it could play within risk or protective factors for individuals.

\section{Results}

The experiences and reflections of individuals serving custodial prison sentences for sexual crime who are practicing ${ }^{1}$ Buddhists map into two main themes, presented in Table 1 below.

Table 1. Superordinate and Subordinate Themes.

\begin{tabular}{ll}
\hline Superordinate Themes & Subordinate Themes \\
\hline & 1.1: Buddhist qualities \\
& 1.2: I can see clearly now \\
1: B: Better future \\
1.4: Attachment is futile \\
1.5: Rose-tinted spectacles \\
\hline 2.1: Karma \\
2: Ebb and flow & 2.3: Acceptance \\
& 2.4: Open to abuse \\
\hline
\end{tabular}

\subsection{Better as a Buddhist}

This superordinate theme articulates the positive qualities that participants expressed they had gained from becoming a Buddhist and engaging in Buddhist practices; this theme reflects participants' beliefs that they had changed their lives and themselves for the better. All the participants explained that the way in which they viewed and interpreted situations had altered, and they had become better people because of their practice.

1 Buddhist training can be divided into three sections: moral discipline, concentration, and wisdom. Moral discipline begins with the observance of precepts, which anchor one's actions in principles of conscientious behavior and moral restraint. Generally, lay Buddhists adhere to five basic precepts: to avoid harming sentient beings, to avoid taking what is not freely given, to avoid sexual misconduct, to avoid harsh or false speech, and to avoid intoxicants including drugs and alcohol. Concentration in the form of meditation is intended to stabilize the mind and clear away the obstacles to the unfolding of wisdom and greater clarity. When applied conscientiously and consistently this structured approach does lead to, amongst other things, greater clarity and insight into the "process" we call "me" (Kumar 2002; Rodrigues 2005). 


\subsubsection{Buddhist Qualities}

One of the most common themes that emerged from the dataset was how participants had changed and how their perception of the world around them had changed since they started practicing Buddhism.

"Buddhists are striving, if they're practicing Buddhists, to erm improve themselves, to improve their perception of the world, be mindful and kind". (Hengist)

Participants asserted that the changes in themselves and their perceptions of the world had come about from an active process of "striving," where individuals actively seek to change the way they think and make decisions. In the extract above, Hengist highlighted the constant development that he (and the others) believed was taking place as their Buddhism encouraged them to constantly strive to be better people. By taking notice of his actions and decisions, Hengist feels he can deliberately choose more positive actions and, over time, become a better person because of his ability to observe himself and to decide to behave in a more positive way (see Maruna 2001). This appeared to be an important Buddhist quality and participants took pride in their increased level of self-awareness and morality. By making the distinction of "practicing Buddhists," Hengist suggests that these skills are not available to other individuals (or to himself previously) and increases his belief that he is better as a Buddhist. It has been asserted that religiosity is frequently the source of desistance for those who manage to live offense-free lives (Hallett and McCoy 2015).

Building insight and understanding our behavior and decision-making is something that is of value not only within Buddhism, but to anyone working within a custodial environment. Many offending behavior programs provided in prison spend a significant amount of time attempting to improve people's insight in their offending behavior to help prevent them from reoffending. For most of the participants, being Buddhist meant being a good person both in the current moment and for the foreseeable future. This takes the insight-building one step further by applying morals to decision-making and making the choice to apply any learning about themselves in a positive manner.

"I think the main value I take from it [Buddhism] is just how to be a better person erm both now and in the future". (Alphonse)

Identifying as a Buddhist appears to promote self-improvement in a way that was apparently not possible for the individual previously. The above extract is one characterized by moral reform in that, through Buddhism, one can become a better person, that is, someone who engages in more pro-social acts and fewer selfish ones. Such narratives of moral reform are common in prisoners who are "getting right with God" (Presser and Kurth 2009). For Alphonse, Buddhism appears to have provided him with a set of guidelines that help him to be a better person. It appears to be not merely personal introspection but the active application of Buddhist principles to their lives that helped them to feel that they were transforming into "good selves" (Perrin and Blagden 2014). Participants highlighted characteristics they had developed since beginning to practice Buddhism; these included being more compassionate and understanding of others' foibles.

“I don't judge anybody you see, I've got no right to judge anybody ... friendship towards other people not to harm other people, you know, just to be an all-round good guy ... not criticize anybody". (Keith B)

"R: so how do you define being a Buddhist?"

"P: erm nice ... yea that's just what it is, it's just being nice". (Alphonse)

All participants reported they had developed and improved themselves through their Buddhist practice; consequently, they also espoused a more positive self-identity of "Buddhist." This master status (Goffman 1963) of "Buddhist" is a helpful move away from a denigrating label, or social curse (Stevenson et al. 2014), which should help them move on from their previous stigmatized 
identity, the "old me" who offended. The qualities they outlined (compassion, being understanding) are presented as not being part of themselves before (i.e., while they were offending); therefore, by developing these qualities, participants are distancing themselves from their offending and the person they were at the time. Not only do they perceive themselves to be better people for having developed themselves through their Buddhist practice, but this also helped to take them further away from their identity as a "sex offender."

\subsubsection{Can See Clearly Now}

This theme encapsulates the notion that becoming Buddhist had helped participants to become more objective in their outlook, and to have a greater awareness of themselves and others. Participants felt that Buddhism had given them a clear purpose and path in life.

"It's more a case of refining the way that I view the world into a way that's more skillful".

(Keith)

"[T]he main thing, by stepping back and thinking about things first and seeing things for what they are straightaway ... it teaches you to see the bigger picture ... you can see the right way of doing something". (Paul Swift)

All participants spoke about how Buddhism helped them think more clearly and gain a better perspective on life. Being Buddhist appeared to allow participants to enter a process of self-reflection. This in turn allowed individuals to change their self-narratives. Presenting a positive self-conception has been demonstrated as leading to positive behavior change (see Presser 2004), becoming a cycle of hope and promise, where a positive self-image leads to positive behavior that further reinforces a positive sense of self. There was a sense not only of being less insular in their thinking and of now being able to see the "bigger picture." Participants also spoke about things appearing to "make sense," and of gaining more structure to their decision-making and problem solving. The notion of now having the right way to approach situations was consistent across participant narratives, the sense that being able to be objective provided them with an ability to deal with situations in a way that non-Buddhists (which included their former selves) could not. The ability to engage in self-reflection and self-evaluation are cornerstones of self-regulation, which in turn can posit behavioral change and contribute to desistance (Göbbels et al. 2012).

This increased clarity was linked with practicing mindfulness and being present in the moment, of paying attention to one's surroundings, thoughts, and emotions. By behaving mindfully, participants felt they developed an increased awareness of situations and were therefore better able to make the "right" decision. Consequently, they gained confidence and self-esteem through acting more mindfully and objectively.

"Mindfulness has to be mindful of, in my view, of things as they are. To see things, the negatives and the positives at the same time, as they are, to see the reality of it because if you start looking at it in a skewed way then I think that's unhealthy". (Keith)

This participant suggests the way that he viewed things previously was detrimental to himself (and perhaps others). The use of "skewed" implies he is aware that he was not perceiving things accurately before, which may have led to unhealthy thoughts or actions. This fits with social information processing theories where misattributions can precipitate harmful and antisocial behavior (see Huesmann 1998).

\subsubsection{Better Future}

Participants asserted that their Buddhist practice helped them both "in the moment" but also to cope with their daily experience of being in custody. Moreover, participants also highlighted how they believed their Buddhist practice offered them a better future, and a chance to atone for their past actions. 
"Buddhism will have a big influence on the way I live from now on ... it's going to keep me safe ... the choices that I make is going to make my life what I want it". (Keith B)

In this extract, Keith B sets out how his Buddhist practice will affect his future life. Keith B is asserting that he will now have control over his life through being able to actively make good choices; he also explains how he will be kept "safe" by Buddhism. Keith B explains Buddhism will, through practices such as mindfulness, through changes in personal characteristics, such as greater self-awareness, and by living in harmony with the Buddhist Noble Truths, allow him to lead a safe and offense-free life.

Participants' narratives in this subtheme also linked to possible future selves. A possible self is a future-orientated construct of "self" formulated by an individual in relation to hopes, fears, and aspirations for the future. Possible selves draw on versions of the self in the past and how they would like to be in the future (Markus and Nurius 1986). Buddhism appeared to be assisting participants to formulate pro-social selves that they wanted to be in the future. The possible self can allow for practical identities to be formed i.e., those that are oriented toward pro-social goals.

Several participants expressed the hope that they would have the opportunity to make amends for their past "unskillful" behavior. Skillful thinking and behavior, the practice of upaya in Mahayana Buddhism, represent intentions rooted in selflessness, kindness, or wisdom as opposed to unskillful means derived from greed, delusion, or hatred (Schroeder 2000). A cultivation of positive mental states allows one to think and act skillfully and with compassion; to associate with others practicing upaya or embracing a similar mind-set encourages one's own practice and adoption of the positive outlook described by the participants.

Participants felt that their future behavior would help them to atone for their previous "unskillful" behavior and that Buddhism offered a framework to understand this change and development of the self in a way that society was not willing to do for someone who had committed a sexual offense. This corresponds with the indication that participants felt shame, guilt, and remorse for their offense and for the bad decisions they had made that led them to that offense. Practicing Buddhism appeared to be a method by which they could atone for past actions and deal with the negative emotions they felt regarding their offending.

"I won't hurt people I love anymore I think Buddhism is, for me, the best thing I can do ... if I can really really get to grips with making myself a good person in prison I can do it really well on the outside so I mean the concept of atonement comes to me a lot, it really really seems a priority for me to atone for what I did. When I get out I can structure my life properly to (A) not do any harm and (B) atone and that will be for the rest of my life". (Hengist)

Here Hengist talks about the structure Buddhism offers him, which helps him to atone for his past behavior. Right now, in prison, with the help of Buddhism, he is becoming a better person, a different person. This narrative shift is an important aspect in the creation of a pro-social identity and for desistance from reoffending. Religious narratives can provide powerful vehicles for people to reinterpret their sense of identity into something far more palatable (Maruna et al. 2006). There are clear links through participants' narratives and within this theme with redemption and atonement for their past (bad) behavior. The redemptive self is a powerful motivator of change because one's identity becomes invested in this narrative of change (McAdams 2006), within the themes here this is achieved through participants' adoption of "Buddhist qualities." In many cultural narratives, common redemptive narratives incorporate forms of atonement (ibid.). A negative emotional event becomes the opening act in a transformative and redemptive sequence. The positive ending, here, being a "new" person, transformed through Buddhism. Here, faith and practice provide people with an enduring sense of positive self-transformation within the identity-defining life story (McAdams et al. 2004). The "redemption script," for example, is characterized by wanting to "give something back" and 
by a recognition that, although individuals cannot change the past, they are aware that no one but themselves can control their present and future (Maruna 2001).

Participants claimed that their Buddhist practice and changed outlook on the world would reduce the likelihood of their reoffending on release. This appeared to stem from being more mindful about their actions, as well as now having the Sangha for support.

"I hope [Buddhism] will help me fit in because erm the world is a valid place out there and I used to be a part of it so I want to stay calm and focused". (John Doe)

"[other Buddhists] would have responded [to my offending] in a different way to the kind of tabloid reaction or propaganda ... they'd see that for what it is [respond] with a very understanding kind of way". (Paul Jones)

For some participants, Buddhism was helping individuals obtain a sense of belonging, to allow them to belong to the world. This is important, particularly with this client group who experience a stigmatizing, hostile, and rejecting world (Jahnke et al. 2015). Indeed, finding "belonging," can act as a protective factor (De Vries Robbé et al. 2015). Participants envisaged a better future due to their Buddhist practice-not only because of the skills they had learned (mindfulness, objectivity, and compassion), but because they would now be part of the Buddhist community. Participants expressed confidence that other Buddhists would accept and forgive them for their offending since Buddhism promulgated compassion and a non-judgmental stance. Participants spoke confidently about the future, downplaying concerns regarding other Buddhists' responses to their offending.

Attachment to a cohesive group, such as a religious community, can indeed be a social cure, bringing numerous wellbeing benefits and mitigating the "social curse" of belonging to a group that is seen as unwanted by society, that of "sex offender" (see Stevenson et al. 2014). Furthermore, the hope of "better futures" and possible selves cannot be underestimated, as research has found that self-identification and positive self-image are significant predictors of post-prison outcomes (LeBel et al. 2008). In contrast, feelings of stigmatization and a fear of being "doomed to deviance" are associated with increased rates of recidivism (McCulloch and McNeill 2008).

\subsubsection{Attachment Is Futile}

This subordinate theme captured participants' aim to have less attachment to things in the future. This fits with the teachings of Buddhism which states that all things are temporary, that attachment equals suffering; thus, Buddhists should try to remove their attachments to (for example) material possessions to reduce personal suffering.

"I get quite attached to people, I make friends and I expect them to be there all the time so when they're not then that gets me down a bit but then I'm learning not to attach myself to people or things". (Paul Swift)

"There really isn't anything called the future there is only the present moment". (Hengist)

Participants spoke about how, since becoming Buddhists, they have tried to adopt a less anxious attitude apropos their relationships with others, following this Buddhist notion of impermanence in life. Being able to step away from attachments might be helpful for those convicted of sexual offenses, who have often lost relationships by virtue of the nature of their offense and have been stripped of possessions as one of the pains of imprisonment (Crewe 2011). Thus, a teaching that helps people to rationalize how attachment could be unhelpful may be a positive for these men, giving meaning to what they have lost.

Attachment to sex was a key area that was highlighted within the interviews and is relevant to the participants' offending. Participants highlighted how they felt Buddhist teachings would help them to manage this in the future. 
"[Sexual] pleasure is an attachment and in forming these attachments with these things erm one teaching of Buddhism is that there is suffering in attachment because you know you either crave for something that you're attached to or you fear that you're going to lose something so there's the suffering in the worrying". (Paul Jones)

Applying the Buddhist notion of non-attachment to sexual preoccupation, a dynamic risk factor for sexual reoffense (Thornton et al. 2003), could be extremely helpful for individuals convicted of a sexual offense. Viewing the need for sexual pleasure as an attachment that causes suffering could help individuals to challenge sexual preoccupation when they experience this and would offer them a framework to support their attempts to detach from sexual drives that may have underpinned their offending.

\subsubsection{Rose-Tinted Buddhist Spectacles}

This theme highlights several challenges with potentially unrealistic expectations around themselves, an exaggerated sense of superiority over non-Buddhists, and a sense that, because they were Buddhists, previous offenses could merely be part of a larger pattern of what was "meant to be." Some participants used Buddhist principles to look at their future in such a positive light that they failed to consider challenges they may face on release. Buddhism was the answer to all problems. Although some participants talked about taking responsibility for their actions and having the choice to do "good," others maintained that "Karma decides" what happens, thus absolving responsibility and removing personal control.

“The way Karma works is that you realize you've done something wrong ... but it maybe gives you an incentive to make sure that in the future you do something incredibly good for people ... to balance out what you've done wrong ... it's a major permission giver isn't it ... if somebody can get away with it in some respect ... that's not the right principles [sic] behind it but that's not to say people don't do it like that". (Alphonse)

In this extract, Karma seems to balance out previous transgressions through doing a "good" act later. This description of Karma also provides a vehicle for the suffering of victims, which could potentially be justified on these grounds. As stated in Alphonse's extract, such a conceptualization may act as a "permission giver," explaining away actions as being "Karma."

\subsection{Ebb and Flow}

This superordinate theme brings together subthemes relating to harmony and equilibrium; it is a balance that comes about through the adjustment of disequilibrium, of constant calibration, and change rather than a result of stasis.

\subsubsection{Karma}

A number of participants discussed how practicing Buddhism has helped them to recognize that their actions are their responsibility, that they have the choice to do good and must accept the consequences of their actions if they do not. Participants spoke about the balancing out of good and bad.

Karma and what this means to the participants was a substantive topic in participants' narratives. It appeared that this had a substantial impact on how the participants made decisions.

"If you dish out bad Karma all the time you're going to end up coming back in these places so try and good Karma and things will go nice ... I find it a lot more enjoyable to erm have good Karma ... I've got a clear conscious I can go back to my cell and I can sleep every night whereas before I found it very difficult". (John Doe)

In the extract above, John Doe describes the notion of Karma as providing himself with a level of inner peace. The emphasis placed on the concept of Karma appears to change how participants feel 
about their life and decision-making. Learning about Karma appears to have provided them with a reason to behave well, which they said they were previously lacking. When practicing Buddhism, behaving positively has the added incentive of providing good Karma, which may motivate individuals to make more positive decisions. The combination of increased responsibility-taking for behavior combined with the morality and ethics taught by Buddhism and the concept of Karma encouraged participants to want to behave in a way they perceived as being "good" or "kind."

"I was just going through this process of trying to understand things ... just looking at me ... why my life had been such a disaster ... the conclusions that I come to was it was, erm, it was my decision erm, no matter how clouded my mind was it was, you know, no matter what I had experienced up to that point, it was still my decision". (Paul Jones)

This links with research that indicates that an internal locus of control has been associated with increased benefit from treatment in a sample of people who had abused children. Further, having an internal locus of control prior to treatment was an important predictor of treatment success (Fisher et al. 1998). Believing they have a choice in their decisions provides the participants with a sense of control over their lives. Combined with the decision to try and do good (as set out in the previous superordinate theme, Better as a Buddhist), a belief in Karma could contribute to the men living a fulfilling and pro-social life in the future. In the extract above, participant Paul Jones twice emphasizes the difficulties he was encountering when he offended. However, he also affirms that he must nevertheless take responsibility for his decisions. The feeling of being in control and taking responsibility for one's actions, as exemplified in an internal locus of control, would be considered a positive outcome for treatment intervention and consequent desistance, certainly for those convicted of sexual offenses (McAnena et al. 2016).

\subsubsection{Emotional Balance}

This theme highlights how participants have used Buddhist practice, and in particular mindfulness and meditation, to help them to manage strong negative emotions including anger and depression. Research has shown that people with sexual convictions can lack emotional management skills; developing skills to be able to deal with unhelpful emotions can be extremely beneficial to such individuals (Gillespie et al. 2012).

"I was going into heavy depressions ... I have to fight the urge to kill myself in all of the negative energy ... using the meditation and skills when I was going through the negative process I was able to get on top of the downward spiral before it was able to get hold of me and drag me down ... I'm able to recognize when it's coming and I can then go and meditate and control it to stop it from coming". (Keith)

This extract suggests that Buddhist practice has provided him with the tools to be able to recognize and manage bouts of depression more effectively using techniques of mindfulness and meditation. Being better equipped to cope with negative emotions will benefit a range of areas of individuals' lives, including relationships, employment, physical health, and desistance of sexual offenses. Another participant reflects on how Buddhism has helped him change his angry outlook on himself and others.

"If I hadn't stumbled across [Buddhism] I'd be really really angry with myself and with everybody else as well ... I wouldn't be, you know, even a vaguely pleasant person I don't think, erm I'd be very very sad as well... It helps you deal with stress it helps you deal with deep emotions and gives you perspective". (Hengist)

Providing a healthy and helpful coping strategy for dealing with emotions, and a better base from which to problem solve ("perspective") is a healthy part of the desistance process (Ward and Mann 2004). 
Participants also talked about how their Buddhist practice and identifying as a Buddhist helped them to deal with the stigma of being labeled as a "sex offender" by providing them with an alternative "good" identity, which they could develop and focus on, relating back to the earlier theme of atonement.

"The normal human being inside you is disgusted and ashamed by it [offending] and the Buddhist inside you perks up a little bit and you are still disgusted and ashamed but you're also, you also understand, it takes account of the fact you can be a better person in the future". (Alphonse)

It is possible that developing a Buddhist identity helps prisoners to cope with the problems of being in custody. By developing and changing themselves during their sentence, they can manage the emotions associated with having their freedom restricted, lacking control, and being away from friends, family, and their normal coping strategies. This positive identity may also provide them with hope for the future, which in turn helps them to cope with the difficulties of serving a custodial sentence, and the pains of imprisonment associated with this (Crewe 2011). In this sense, changes in identity through Buddhist practice strike at the heart of the "Good Lives Model (GLM) of offender rehabilitation (see Ward and Stewart 2003; Ward and Marshall 2007). The GLM aims to help offenders construct more adaptive narrative identities while also giving the offender the tools to enable them to attain those goods which are important to them post-release. This parallels Vaughan's (2007) argument that change in one's internal narrative identity comes from a reconsolidation of their ultimate concerns. There is evidence to suggest that religion can represent the core from which many of these mechanisms can flourish and assist the desistance process in offenders (Perrin et al. 2018).

\subsubsection{Acceptance}

This subtheme highlights how the participants described their approach to problems in life as a Buddhist. They spoke about the notion of "impermanence": that things are constantly changing. Participants explained that this helped them to accept how things are in the present moment and to reduce craving and desire for things to be different.

“You shouldn't crave for things because craving is what causes the suffering...be satisfied with how it is there and then...things are forever changing, nothing stays the same, people come and go". (Paul Swift)

Paul Swift states you "shouldn' $\mathrm{t}$ " crave for things. Here he is setting himself a strict rule which he reports to live by. It appears this is an ideal to strive for rather than being an easy goal to achieve as he later highlights how he does experience cravings and struggles to stay "in the moment" at times.

"I'm more focused ... more considered kind of life ... how to respond on a daily basis in a better way ... look at the chain of consequences". (Paul Jones)

Here, Paul Jones uses the concept of acceptance to explain how he approaches situations. By considering how behavior and thoughts impact each other allowed him to make better decisions. One participant described getting to the "it-doesn't-matter" stage before getting annoyed and frustrated with a person or problem. This highlights how accepting the current moment can help the participants to manage difficult situations: to the Buddhist, since things are not permanent, but will change, one simply needs to wait as negative feelings will not last.

“It takes a lot of time even now I sort of get annoyed with certain things people's actions but again it's just a passing moment". (Paul Swift)

\subsubsection{Open to Abuse}

One further element to this subtheme was the idea that Buddhist prisoners are left vulnerable within the establishment due to the nature of their beliefs and their practice. Practicing Buddhist 
principles and being thoughtful of others allows individuals to take advantage of them. The fact that other individuals do not live by the same principles that they do leaves them open to potential victimization.

"Because of our um giving freely people will take advantage of it they'll come into my cell and they'll say I want a cigarette by rights I have to give them one coz they've asked you know I give freely but some of them jump on board and they use that excuse to say oh I want this I want that you know I don't say anything, it's not my problem, they're the ones with the problem not me you know, if I've got it they can have it, if I haven't got it they don't [fully] stop ... you've got to be very careful you can be taken advantage of". (Keith)

Within this extract, Keith acknowledges his duty to give freely as a Buddhist, but he also appears to resent this at times.

\section{Discussion}

This research highlights how participants serving custodial sentences for a sexual offense perceive that they have changed through becoming a Buddhist and engaging in Buddhist practices. Participants reported how they used Buddhism to cope with daily life within custody as well as to develop themselves into "better," more pro-social individuals ready for release. While the sample size was modest, it was appropriate for the phenomenological method used, which requires detailed analysis of rich, idiographic data. It should be acknowledged that the sample was self-selecting and constituted 15 percent of the Buddhist population in the prison.

So why Buddhism? The current study with prisoners who identify as Buddhist is part of a larger research program with individuals of different faiths (see Winder et al. 2018; Blagden et al. 2018). Research on the link between recidivism and religion has demonstrated a weak association between the two (Johnson 2004): research such as this has, however, led to calls for more research on the impact of religious involvement and, in particular, faith-based treatment programs in prison (see, for example, Thomas and Zaitzow 2006). Alongside quantitative studies, it is important to undertake qualitative research that helps to inform our understanding of the theoretical and clinical basis for any statistical relationships. The current study was designed to achieve this idiographic exploration of Buddhist faith and practice.

One of the main aims of cognitive-behavioral-based interventions (the main form of intervention in the UK prison service) is to provide individuals with skills that they lack, which may have contributed to their offending. Participants highlighted how Buddhism and their Buddhist practice had enabled them to develop in ways that improved their emotional regulation and their problem solving skills and to develop an internal locus of control. These are all psychologically meaningful risk factors related to committing sexual offenses (Mann et al. 2010). Indeed, several parallels between Buddhist teachings and skills taught in offending behavior programs became apparent. Both appear to encourage individuals to change unhelpful negative behaviors, both encourage insight and consideration of problems and feelings and both support building healthier, more content identities while reducing harm to others. As noted in the analysis, Buddhist practice had links to the GLM of offender rehabilitation, a strength-based treatment approach, which moves away from focusing on risk factors and instead looks to galvanize any pro-social traits in offenders (Ward and Stewart 2003). The GLM aims to help offenders construct more adaptive narrative identities, and some participants articulated that their Buddhist practices assisted in the transition to more positive/good selves. What is apparent is how both programs and Buddhism have the potential to support each other in assisting people who have committed a sexual offense to live an offense-free life. This is possibly unusual. Typically, the chaplaincy works separately form offending behavior programs, and therapists may fear or avoid touching on areas relating to an individuals' faith, for fear of offense or accusations of prejudice (Wakame 2014). However, it is important that the existence and impact of the beliefs presented by religious individuals are not avoided by the prison service. Religious illiteracy (Moore 2007) amongst 
therapists working with individuals convicted of sexual offenses hinders the unravelling of faith-linked rationalizations for offending behavior, an integral part of cognitive-behavioral treatment programs.

From understanding Buddhist practices, there seemed to be a substantial number of benefits for participants. Indeed, some of the Buddhist practices such as mindfulness and compassion are being adopted into mainstream, secular treatment programs. However, as with any faith, misunderstandings are indubitably going to arise apropos beliefs and practices that may foster unhealthy attitudes or behavior by adherents. Prisoners, in their somewhat isolated existence, may cultivate to extreme faith-based attitudes or behavior, some of which may be unhealthy for this particular service user group. The main example of this here is regarding attachment; while participants highlighted how Buddhism would discourage having attachments (toward people or objects), research has demonstrated that having an emotionally intimate relationship with a partner (which would involve an attachment) can help to protect individuals from further sexual offenses. This is a clear conflict between what an individual's Buddhist practice may tell them and what professionals involved in helping someone to remain offense-free may encourage. Of course, having an emotionally intimate relationship (or an attachment) is not the sole factor involved in remaining offense-free and it is possible that someone could live pro-socially without this; however, it is an element that could cause conflict for individuals who are incarcerated for a sexual offense and who are Buddhist. Another example of Buddhist practice potentially conflicting with risk management is the idea that the future does not exist. This concept is linked to mindfulness and that individuals should live in the moment as much as possible. Although most participants were realistic about needing to plan for the future, it is possible that some Buddhist prisoners may choose not to do this, choosing to manage themselves in the moment instead. This could be problematic for an individual as they would not be foreseeing any potential consequences of their actions or anticipating any future risk that could be a result of their actions or behavior. Previous research has found that religion could be used in self-serving ways by individuals who interpreted religious doctrine in a way that allowed them to justify their behavior, exacerbating their offending (Topalli et al. 2013).

It should also be acknowledged that this research cannot comment on the utility (or otherwise) of Buddhist practices in the community. Feeling accepted by a community can be an important protective factor for desistance by individuals with sexual convictions; the current study is unable to comment on the experiences of Buddhist participants in the community, nor the participants' ability or desire to continue to practice Buddhism when they are released. Future studies would find a useful area to explore.

\section{Materials and Methods}

\subsection{Participants}

The sample consisted of seven adult males convicted of a sexual offense who were currently serving sentences at a UK prison that specializes in working with men convicted of such offenses. Although the sample size is modest, thorough analysis of the data was prioritized over a larger sample size, as this allowed a richer exploration of the idiographic data.

Participants were all white and British, with a mean age of 42 (SD: 16.02). All participants had completed an offending behavior program-either a specialist sex offender treatment program or a living skills program. The inclusion criteria for the research were prisoners serving a custodial sentence for a sexual offense and identifying themselves as Buddhist. The sample comprised 15 percent of the Buddhist population at the prison.

Participants' names were changed to pseudonyms to protect their identities and provide them with anonymity throughout the study. See Table 2 for information regarding the participants. 
Table 2. Participant information.

\begin{tabular}{cclll}
\hline $\mathbf{P}$ & Pseudonym & \multicolumn{1}{c}{ Occupation } & \multicolumn{1}{c}{$\begin{array}{c}\text { Religious before/after } \\
\text { Offending }\end{array}$} & \multicolumn{1}{c}{$\begin{array}{c}\text { Offending Behavior } \\
\text { Programmes Completed }\end{array}$} \\
\hline 1 & Hengist & $\begin{array}{l}\text { Worked on night club doors } \\
\text { and pub doors }\end{array}$ & Discovered Buddhism in prison & Core SOTP \\
\hline 2 & Alphonse & Student & Buddhist since age 8 & Thinking Skills Programme \\
\hline 3 & Paul Swift & $\begin{array}{l}\text { Only in the community for a } \\
\text { short time, worked as a } \\
\text { joiner, as a barman, and in a } \\
\text { burger bar }\end{array}$ & $\begin{array}{l}\text { Raised Church of England, } \\
\text { discovered Buddhism in prison }\end{array}$ & $\begin{array}{l}\text { Core SOTP; Enhanced } \\
\text { Thinking Skills; Controlling } \\
\text { Anger and Learning to } \\
\text { Manage It }\end{array}$ \\
\hline 4 & Keith & $\begin{array}{l}\text { Medically } \\
\text { retired/previously a } \\
\text { lorry driver }\end{array}$ & Discovered Buddhism in prison & $\begin{array}{l}\text { Becoming New Me SOTP; } \\
\text { Adapted Better Lives Booster }\end{array}$ \\
\hline 5 & Keith B & $\begin{array}{l}\text { Emergency Medical } \\
\text { Technician }\end{array}$ & $\begin{array}{l}\text { Raised Church of England; } \\
\text { practicing Buddhism at times } \\
\text { throughout life }\end{array}$ & $\begin{array}{l}\text { Thinking Skills Programm; } \\
\text { Core SOTP; Extended SOTP }\end{array}$ \\
\hline 6 & John Doe & Electrician & Raised Roman Catholic & $\begin{array}{l}\text { Prison-Addressing } \\
\text { Substance-Related Offending; } \\
\text { Enhanced Thinking Skills; } \\
\text { Core SOTP; Extended SOTP }\end{array}$ \\
\hline 7 & Paul Jones & Police Officer & Discovered Buddhism in prison & Core SOTP \\
\hline
\end{tabular}

\subsection{Data Collection}

Access to participants was granted following ethical approval by Her Majesty's Prison Service and a UK university. Potential participants were recruited via visiting the establishment Buddhist group, posters on the wings, and an interview on the prison radio station. Volunteers contacted the lead researcher who arranged an information and consent appointment with potential participants.

All participants were interviewed on a one-to-one basis by one of the researchers in a private room within the prison, offering a respectful environment for participants to discuss their experiences. Each interview was recorded on a passcode-protected dictaphone and transcribed verbatim.

Interviews

The data were collected through semi-structured interviews, which lasted between 1.5 and $3 \mathrm{~h}$. The interview schedule was developed from that used for previous research investigating Christianity within this population (Winder et al. 2018), and the questions were adapted to reflect the differences between Buddhism and the Christian faith. The questions were categorized into five main sections:

1. questions about their Buddhist practice and the values they associated with this;

2. self, home and family environment, and personal information (such as occupation and age);

3. their Buddhist beliefs in relation to their offending;

4. treatment interventions and their Buddhist beliefs;

5. future plans, goals, and coping outside prison.

\subsection{Analysis}

The research utilized the analytic method of interpretative phenomenological analysis (IPA). This method was chosen as its aim is to explore the lived experience of individuals and the meaning they attribute to that, while also acknowledging and including the impact of the researchers' interpretations.

IPA is concerned with the quality of the experience rather than with the identification of cause-effect relationships (Willig 2013). This means it can attempt to explain events and experiences but cannot predict them. Although it is subjective, it is systematic. Through analyzing the semi-structured interviews, we aimed to facilitate the understanding of experiences of Buddhist individuals convicted of a sexual offense. Analysis was guided by previous precedents (see, for example, Smith 2004; 
Smith and Osborn 2008), entailing a detailed reading and re-reading of transcripts, the production of notes pertaining to possible subordinate themes, and the systematic generation and clustering of subordinate themes into superordinate themes.

\section{Conclusions}

It appears that many aspects of Buddhism could be helpful for individuals both on a risk management and a personal level. The interviews highlighted how Buddhism has the potential to act as a protective factor for some individuals by helping them to build insight and awareness, as well as skills to manage emotions, become part of a pro-social community, and develop morality and compassion toward themselves and others. These are all positive elements and it was clear from the research how much the participants felt they had benefited from their Buddhist practice.

One concern was the potential for misinterpretation from individuals, despite clear guidance from the Buddhist Chaplain. It is possible that individuals will the Buddhist teachings in their own way; in fact, one element of Buddhist teaching pertains to about taking responsibility and making up your own mind about how to behave (The Eightfold Path). This could potentially lead to individuals choosing risky behaviors and justifying them either with Karma or through cognitive distortions.

One outcome of the research was the idea of teaching ethics alongside mindfulness in order to promote compassion and kindness. This is something that the participants and the Buddhist Chaplain were passionate about when discussing the use of mindfulness within interventions. As the concept of mindfulness comes from Buddhism this is particularly relevant, and it is interesting that compassion-based therapy is becoming more popular within psychology. This could suggest an increase in the belief that building compassion can help to improve individuals' lives.

One positive outcome from this research is that all participants noted a need and a motivation to make changes to themselves, and a wish to be offense-free in future. Participants all spoke hopefully about being able to manage their risk in the community. Although there is no clear indication that Buddhist practice in itself reduces the risk of sexual recidivism, it appears to provide adherents with an element of hope and motivation to change. Emerging evidence would indicate that this is a positive finding indeed.

Acknowledgments: No funding was requested or received for this research. Sincere and grateful thanks CM who kindly performed the most thorough proof reading known to humankind. Any errors have undoubtedly been added back in by the authors. Many thanks to Imogen Byrne, at Nottingham Trent University, for her painstaking work in helping to prepare the paper. Thanks also to the participants who gave up their time to talk to us, and to Lynn Saunders, Governor of HMP Whatton, and Jo Honour, who was previously Coordinating Chaplain at HMP Whatton, for supporting this research.

Author Contributions: B.W. and N.B. conceived and designed the experiments; K.B. performed the interviews; B.W. and K.B. analyzed the data; N.B. contributed materials/analysis; K.B., B.W. and N.B. wrote the paper.

Conflicts of Interest: The authors declare no conflict of interest.

\section{References}

Beckstead, A. Lee. 2012. Can we change sexual orientation? Archives of Sexual Behavior 41: 121-34. [CrossRef] [PubMed]

Beier, Klaus M., Christoph J. Ahlers, David Goecker, Janina Neutze, Ingrid A. Mundt, Elena Hupp, and Gerard A. Schaefer. 2009. Can pedophiles be reached for primary prevention of child sexual abuse? First results of the Berlin Prevention Project Dunkelfeld (PPD). The Journal of Forensic Psychiatry \& Psychology 20: 851-67.

Blagden, Nicholas, Winder Belinda, and Lievesley Rebecca. 2018. "The resurrection after the old has gone and the new has come": Understanding narratives of forgiveness, redemption and resurrection in Christian individuals serving time in custody for a sexual offence. (under review).

Bowen, Sarah, Katie Witkiewitz, Tiara M. Dillworth, Neharika Chawla, Tracy L. Simpson, Brian D. Ostafin, Mary E. Larimer, Arthur W. Blume, George A. Parks, and G. Alan Marlatt. 2006. Mindfulness meditation and substance use in an incarcerated population. Psychology of Addictive Behaviors 20: 343-47. [CrossRef] [PubMed] 
Clear, Todd R., and Melvina T. Sumter. 2002. Prisoners, prison, and religion: Religion and adjustment to prison. Journal of offender Rehabilitation 35: 125-56. [CrossRef]

Clear, Todd R., Patricia L. Hardyman, Bruce Stout, Karol Lucken, and Harry R. Dammer. 2000. The value of religion in prison: An inmate perspective. Journal of Contemporary Criminal Justice 16: 53-74. [CrossRef]

Crewe, Ben. 2011. Depth, weight, tightness: Revisiting the pains of imprisonment. Punishment \& Society 13: 509-29.

De Vries Robbé, Michiel, Ruth E. Mann, Shadd Maruna, and David Thornton. 2015. An exploration of protective factors supporting desistance from sexual offending. Sexual Abuse 27: 16-33. [CrossRef] [PubMed]

Derezotes, David. 2000. Evaluation of yoga and meditation trainings with adolescent sex offenders. Child and Adolescent Social Work Journal 17: 97-113. [CrossRef]

Dunn, James M. 2010. Benefits of Mindfulness Meditation in a Corrections Setting. Available online: https: / / www.upaya.org/uploads/pdfs/DunnBenefitsofMeditationinCorrectionsSettingrev7110.pdf (accessed on 18 March 2018).

Eshuys, Donna, and Stephen Smallbone. 2006. Religious affiliations among adult sexual offenders. Sexual Abuse: A Journal of Research and Treatment 18: 279-88. [CrossRef] [PubMed]

Fisher, Dawn, Anthony Beech, and Kevin Browne. 1998. Locus of control and its relationship to treatment change and abuse history in child sexual abusers. Legal and Criminological Psychology 3: 1-12. [CrossRef]

Gillespie, Steven M., Ian J. Mitchell, Dawn Fisher, and Anthony R. Beech. 2012. Treating disturbed emotional regulation in sexual offenders: The potential applications of mindful self-regulation and controlled breathing techniques. Aggression and Violent Behavior 17: 333-43. [CrossRef]

Göbbels, Svenja, Tony Ward, and Gwenda M. Willis. 2012. An integrative theory of desistance from sex offending. Aggression and Violent Behavior 17: 453-62. [CrossRef]

Goffman, Erving. 1963. Stigma: Notes on a Spoiled Identity. New York: Jenkins, JH \& Carpenter.

Hallett, Michael, and J. Stephen McCoy. 2015. Religiously motivated desistance: An exploratory study. International Journal of Offender Therapy and Comparative Criminology 59: 855-72. [CrossRef] [PubMed]

Harper, Craig A., Todd E. Hogue, and Ross M. Bartels. 2017. Attitudes toward sexual offenders: What do we know, and why are they important? Aggression and Violent Behavior 34: 201-13. [CrossRef]

Huesmann, L. Rowell. 1998. The role of social information processing and cognitive schema in the acquisition and maintenance of habitual aggressive behavior. In Human Aggression. Amsterdam: Elsevier Inc., pp. 73-109.

Jahnke, Sara, Roland Imhoff, and Juergen Hoyer. 2015. Stigmatization of people with pedophilia: Two comparative surveys. Archives of Sexual Behavior 44: 21-34. [CrossRef] [PubMed]

Johnson, Byron R. 2004. Religious programs and recidivism among former inmates in prison fellowship programs: A long-term follow-up study. Justice Quarterly 21: 329-54. [CrossRef]

Kewley, Stephanie, Anthony R. Beech, and Leigh Harkins. 2015. Examining the role of faith community groups with sexual offenders: A systematic review. Aggression and Violent Behaviour 25: 142-49. [CrossRef]

Kewley, Stephanie, Michael Larkin, Leigh Harkins, and Anthony R. Beech. 2016. Restoring identity: The use of religion as a mechanism to transition between an identity of sexual offending to a non-offending identity. Criminology \& Criminal Justice 17: 79-96.

Khoury, Bassam, Tania Lecomte, Guillaume Fortin, Marjolaine Masse, Phillip Therien, Vanessa Bouchard, Marie-Andrée Chapleau, Karine Paquin, and Stefan G. Hofmann. 2013. Mindfulness-based therapy: A comprehensive meta-analysis. Clinical Psychology Review 33: 763-71. [CrossRef] [PubMed]

Kumar, Sameet M. 2002. An introduction to Buddhism for the cognitive-behavioral therapist. Cognitive and Behavioral Practice 9: 40-43. [CrossRef]

LeBel, Thomas P., Ros Burnett, Shadd Maruna, and Shawn Bushway. 2008. The chicken and egg of subjective and social factors in desistance from crime. European Journal of Criminology 5: 131-59. [CrossRef]

Mann, Ruth E., R. Karl Hanson, and David Thornton. 2010. Assessing risk for sexual recidivism: Some proposals on the nature of psychologically meaningful risk factors. Sexual Abuse 22: 191-217. [CrossRef] [PubMed]

Markus, Hazel, and Paula Nurius. 1986. Possible selves. American Psychologist 41: 954-69. [CrossRef]

Maruna, Shadd. 2001. Making Good. Washington: American Psychological Association.

Maruna, Shadd, Louise Wilson, and Kathryn Curran. 2006. Why God is often found behind bars: Prison conversions and the crisis of self-narrative. Research in Human Development 3: 161-84.

McAdams, Dan P. 2006. The problem of narrative coherence. Journal of Constructivist Psychology 19: 109-25. [CrossRef] 
McAdams, Dan P., Nana Akua Anyidoho, Chelsea Brown, Yi Ting Huang, Bonnie Kaplan, and Mary Anne Machado. 2004. Traits and stories: Links between dispositional and narrative features of personality. Journal of Personality 72: 761-84. [CrossRef] [PubMed]

McAnena, Caoimhe, Jackie Craissati, and Kelly Southgate. 2016. Exploring the role of locus of control in sex offender treatment. Journal of Sexual Aggression 22: 95-106. [CrossRef]

McCulloch, Trish, and Fergus McNeill. 2008. Desistance-Focused Approaches. Cullompton: Willan, vol. 154.

McGuire, James. 2013. 'What Works' to Reduce Re-Offending. Available online: https:/ / onlinelibrary.wiley.com/ doi/10.1002/9781118320655.ch2 (accessed on 14 February 2018).

Moore, Diane. 2007. Overcoming Religious Illiteracy: A Cultural Studies Approach to the Study of Religion in Secondary Education. New York: Springer.

O'Connor, Thomas P. 2005. What works, religion as a correctional intervention: Part II. Journal of Community Corrections 14: 4-26.

Offender Management Service. 2016. Annual National Offender Management Service Digest: 2016 to 2017. Available online: https://www.gov.uk/government/statistics/annual-national-offender-managementservice-digest-2016-to-2017 (accessed on 29 March 2018).

Office for National Statistics. 2015. Focus on Violent Crime and Sexual Offences: Year Ending March 2015. Available online: https://www.ons.gov.uk/peoplepopulationandcommunity/crimeandjustice/ compendium/focusonviolentcrimeandsexualoffences/yearendingmarch2015 (accessed on 29 March 2018).

Perrin, Christian, and Nicholas Blagden. 2014. Accumulating meaning, purpose and opportunities to change 'drip by drip': The impact of being a listener in prison. Psychology, Crime E Law 20: 902-20.

Perrin, Christian, Nicholas Blagden, Belinda Winder, and Christine Norman. 2018. Religion and Desistance: Working with Sexual and Violent Offenders. In Finding Freedom in Confinement: The Role of Religion in Prison Life. Santa Barbara: ABC-CLIO.

Presser, Lois. 2004. Violent offenders, moral selves: Constructing identities and accounts in the research interview. Social Problems 51: 82-101. [CrossRef]

Presser, Lois, and Suzanne Kurth. 2009. I got a quick tongue': Negotiating ex-convict identity in mixed company. In How Offenders Transform Their Lives. London: Routledge, pp. 72-86.

Rodrigues, Jennifer. 2005. Presence, Clarity and the Space of Receptivity in Counselling: Shambhala Buddhist Counsellors' Narratives of Experience. Ph.D. dissertation, University of British Columbia, Vancouver, BC, Canada.

Salas-Wright, Christopher P., Margaret Lombe, Michael G. Vaughn, and Brandy R. Maynard. 2016. Do adolescents who regularly attend religious services stay out of trouble? Results from a national sample. Youth $\mathcal{E}$ Society 48: 856-81.

Schroeder, John. 2000. Nagarjuna and the Doctrine of 'Skillful Means'. Philosophy East \& West 50: 559-83.

Simpson, Tracy L., Debra Kaysen, Sarah Bowen, Lorna M. MacPherson, Neha Chawla, Arthur Blume, G. Alan Marlatt, and Mary E. Larimer. 2007. PTSD symptoms, substance use, and vipassana meditation among incarcerated individuals. Journal of Traumatic Stress 20: 239-49. [CrossRef] [PubMed]

Smith, Jonathan A. 2004. Reflecting on the development of interpretative phenomenological analysis and its contribution to qualitative research in psychology. Qualitative Research in Psychology 1: 39-54.

Smith, Jonathan A., and Mike Osborn. 2008. Interpretative phenomenological analysis. In Qualitative Psychology: A Practical Guide to Research Methods. London: SAGE, pp. 51-80.

Stevenson, Clifford, Niamh McNamara, and Orla Muldoon. 2014. Stigmatised identity and service usage in disadvantaged communities: Residents', community workers' and service providers' perspectives. Journal of Community \& Applied Social Psychology 24: 453-66.

Thomas, Jim, and Barbara H. Zaitzow. 2006. Conning or conversion? The role of religion in prison coping. The Prison Journal 86: 242-59. [CrossRef]

Thornton, David, Ruth Mann, Steve Webster, Linda Blud, Rosie Travers, Caroline Friendship, and Matt Erikson. 2003. Distinguishing and combining risks for sexual and violent recidivism. Annals of the New York Academy of Science 989: 225-35. [CrossRef]

Topalli, Volkan, Timothy Brezina, and Mindy Bernhardt. 2013. With God on my side: The paradoxical relationship between religious belief and criminality among hardcore street offenders. Theoretical Criminology 17: 49-69. [CrossRef]

Vaughan, B. 2007. The internal narrative of desistance. British Journal of Criminology 47: 390-404. [CrossRef] 
Wakame, Simone. 2014. Working with the religious and cultural beliefs of offenders. Paper presented at HMP Whatton Conference, Nottinghamshire, UK, June 11.

Ward, Tony, and Ruth Mann. 2004. Good lives and the rehabilitation of offenders: A positive approach to sex offender treatment. In Positive Psychology in Practice. Hoboken: Wiley, pp. 598-616.

Ward, Tony, and Bill Marshall. 2007. Narrative identity and offender rehabilitation. International Journal of Offender Therapy and Comparative Criminology 51: 279-97. [CrossRef] [PubMed]

Ward, Tony, and Claire Stewart. 2003. The treatment of sex offenders: Risk management and good lives. Professional Psychology: Research and Practice 34: 353-60. [CrossRef]

Willig, Carla. 2013. Introducing Qualitative Research in Psychology. London: McGraw-Hill Education.

Winder, Belinda, Kerensa Hocken, and Emma Allen. 2017. The Safer Living Foundation and the SLF Prevention Project. Paper presented at Crime in Mind Conference, Nottinghamshire, UK, November 17.

Winder, Belinda, Nicholas Blagden, and Rebecca Lievesley. 2018. Because you've got faith it doesn't mean that you've got wings on your back: A qualitative analysis of the accounts of Christian individual's serving time in custody for a sexual offence. (in press)

(C) 2018 by the authors. Licensee MDPI, Basel, Switzerland. This article is an open access article distributed under the terms and conditions of the Creative Commons Attribution (CC BY) license (http://creativecommons.org/licenses/by/4.0/). 